\title{
Personal protective equipment penetration performance may be affected by temperature and humidity
}

\author{
Betul Basaran, MD, DESA (1) - Sena Tolu, MD
}

Received: 28 February 2021 /Revised: 4 March 2021 / Accepted: 5 March 2021/Published online: 24 May 2021

(c) Canadian Anesthesiologists' Society 2021

To the Editor,

We read with interest the recent article by Wild et al. on the importance of wearing higher protection level gowns during aerosol-generating procedures. ${ }^{1}$ Their simulation study was mainly based on the penetration of contrast medium diluted with water through different types of gowns. Nevertheless, it has been shown that different ambient, body, and test fluid temperatures and also different types of test fluid may affect the penetration process. $^{2}$ Moreover, wearing personal protective equipment (PPE) might pose a thermoregulation risk to the practitioner by increasing core body temperature. As a result, penetration may increase while working with PPE because of the effects of elevated core body temperature. Furthermore, since the penetration of dye was observed after ten minutes in Wild et al.'s study, the humidity of the environment may also affect the drying process. ${ }^{3}$ An environment with higher humidity may delay the drying process and lead to an increase in the penetration of test fluid through the gown. High-risk situations like aerosolgenerating procedures during the COVID-19 pandemic may occur in a variety of environments other than the intensive care unit or operating room. On the basis of the

This letter is accompanied by a reply. Please see Can J Anesth 2021; this issue.

B. Basaran, MD, DESA ( $\square)$

Department of Anesthesiology and Reanimation, School of

Medicine, Karamanoglu Mehmetbey University, Karaman,

Turkey

e-mail: betulbasaran1@yahoo.com

S. Tolu, MD

Department of Physical Medicine and Rehabilitation, School of Medicine, Medipol University, Istanbul, Turkey above, we would suggest that testing higher-level PPE at different ambient and body temperatures as well as during exposure to different levels of environmental humidity and body fluids would provide additional helpful information about their protection levels.

Disclosures None.

Funding statement None.

Editorial responsibility This submission was handled by Dr. Stephan K.W. Schwarz, Editor-in-Chief, Canadian Journal of Anesthesia/Journal canadien d'anesthésie.

\section{References}

1. Wild E, Zasso FB, You-Ten KE. Are the garment seams a potential source of breach in level-4 personal protective equipment gowns? Can J Anesth 2021; DOI:https://doi.org/10.1007/s12630-02101913-7.

2. Cao W, Cloud R. Effects of temperature on liquid penetration performance of surgical gown fabrics. Int J Cloth Sci Technol 2010; 22: 319-32.

3. Basaran B, Tolu S. Reporting drying temperature and humidity may give more standardised results. Int J Obstet Anesth 2021; DOI:https://doi.org/10.1016/j.ijoa.2021.102967.

Publisher's Note Springer Nature remains neutral with regard to jurisdictional claims in published maps and institutional affiliations. 